Viso - Cadernos de estética aplicada

Revista eletrônica de estética

ISSN 1981-4062

No 9, jul-dez/2010

http://www.revistaviso.com.br/
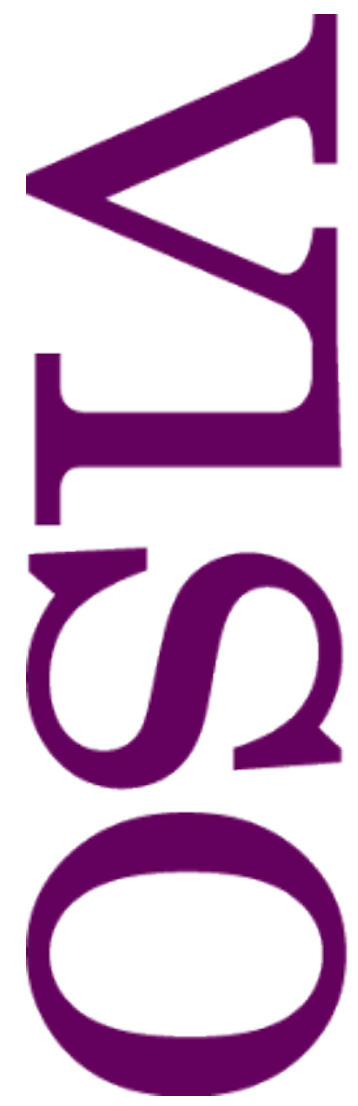

\title{
Elogio da Loucura por Campos de Carvalho Luisa Buarque
}




\section{RESUMO}

\section{Elogio da Loucura por Campos de Carvalho}

Em 1972, o autor Campos de Carvalho publica uma série de crônicas no Pasquim, reunidas e lançadas em um pequeno livro, trinta anos mais tarde. Em uma delas, apresenta-se uma espécie de dialética da loucura e da normalidade que, de alguma forma, pode ser aproximada de certas ideias contidas tanto em O Mito de Sísifo, de Camus, quanto em O Nascimento da Tragédia, de Nietzsche. O presente artigo propõe uma interpretação dessa crônica literária, sob a luz das referidas filosofias.

Palavras-chave: loucura - Camus - absurdo - Nietzsche - dionisíaco - vida - morte

\section{ABSTRACT}

\section{Campos de Carvalho's Praise of Folly}

n the year of 1972, Campos de Carvalho publishes a series of chronicles in the Brazilian journal called Pasquim, chronicles that have appeared in a small book, thirty years later. In one of them, a kind of dialectics of madness and normality shows itself, and this dialectics can probably be approached from certain ideas contained both in The Myth of Sisyphus, from Camus, and in The Birth of Tragedy, from Nietzsche. This article proposes an interpretation of this literary chronicle, in the light of that mentioned philosophies.

Keywords: folly - Camus - absurd - Nietzsche - dionysian - life - death 


\section{BUARQUE, L. "Elogio da Loucura por Campos de Carvalho". In: Viso: Cadernos de estética aplicada, v. IV, n. 9 (jul-dez/2010), pp. 12-19.}

DOI: 10.22409/1981-4062/v9i/96

Aprovado: 21.07.2011. Publicado: 17.08.2011.

(C) 2011 Luisa Buarque. Esse documento é distribuído nos termos da licença Creative Commons Atribuição-NãoComercial 4.0 Internacional (CC-BY-NC), que permite, exceto para fins comerciais, copiar e redistribuir o material em qualquer formato ou meio, bem como remixá-lo, transformá-lo ou criar a partir dele, desde que seja dado o devido crédito e indicada a licença sob a qual ele foi originalmente publicado.

Licença: http://creativecommons.org/licenses/by-nc/4.0/deed.pt_BR

Accepted: 21.07.2011. Published: 17.08.2011.

(C) 2011 Luisa Buarque. This document is distributed under the terms of a Creative Commons Attribution-NonCommercial 4.0 International license (CC-BY-NC) which allows, except for commercial purposes, to copy and redistribute the material in any medium or format and to remix, transform, and build upon the material, provided the original work is properly cited and states its license.

License: http://creativecommons.org/licenses/by-nc/4.0/ 
Nada se edifica sobre a pedra, tudo sobre a areia, mas nosso dever é edificar como se fora pedra a areia. Jorge Luis Borges

Foi recentemente lançado um pequeno livro de Walter Campos de Carvalho intitulado Cartas de viagem e outras crônicas, contendo, como nos informa a apresentação de Antonio Prata, as únicas palavras escritas pelo autor "no longo silêncio que se estendeu de 1964, ao colocar o ponto final no Púcaro Búlgaro, até a hora de sua morte, na sextafeira santa de 1998". Trata-se de algumas das crônicas que foram publicadas no Pasquim, em 1972. As primeiras delas são pequenas cartas que o autor escreveu para si mesmo durante uma viagem à Europa, contendo observações agudas, cheias de humor e de intransigência, acerca de cidades como Londres, Paris e Barcelona. A seguir, encontram-se diversas crônicas esparsas e sem aparente conexão temática, mas absolutamente reveladoras não apenas do estilo do autor, mas também da visão de mundo que rasteja pelos interstícios de suas palavras, de suas frases, de seus livros.

A segunda parte do livro, que se segue às cartas de viagem, se inicia com uma crônica sem título, cujo assunto perpassa muitas das obras do autor, e não por acaso. "Não fui claune", alega o narrador na frase de abertura, "mas em compensação já passei por louco muitas vezes". ${ }^{1}$ Está exposto, logo na primeira sentença, o tema em torno do qual se desenrolará esse curto texto cheio de alusões e de sugestões: a loucura vista como lucidez extrema, consciência demais diante de uma realidade tacanha, baseada em ilusões mesquinhas e medíocres. $E$, ademais, o palhaço visto como o parente mais próximo do louco, dentre os sãos, porque revira a normalidade do avesso, dá cambalhotas e faz rir dos alegados prumos e nortes. Claune e louco, na construção narrativa da crônica, são aqueles que mostram o verdadeiro desequilíbrio no aparente equilíbrio daquilo que comumente chamamos de normalidade, ou ainda, de nossa vida comum e cotidiana: "geringonça de engonço frágil como uma libélula". ${ }^{2}$ Estamos, como nos revela o narrador, sob o gládio da loucura, esse "zênite da sabedoria", porque, no limbo em que vivemos - em nossa constante inconsciência e recusa em olhar para o que mais importa sob o pretexto de estar a olhar para o mais importante e extremamente sério - corremos sempre o risco de sermos cortados por essa lucidez extrema da loucura. Com as metáforas da luz, da consciência, da visão aguçada, a loucura aparece no texto de Campos de Carvalho, portanto, como o saber: o conhecimento de algo que está encoberto por essa realidade comum que procura ser a única, totalitária, de potência universal, mas que se revela, no entanto, frágil e instável.

Muito haveria a ser dito acerca daquilo que aparece no texto como sendo o objeto dessa sabedoria mais profunda, e que resta encoberto pela realidade comum, mas parece-me que há duas passagens especialmente alusivas no tocante a essa questão: na primeira, o autor se refere à humanidade como "moscas que somos ou o micróbio da mosca" ${ }^{4}$, e na segunda delas afirma "que tudo é afinal apenas um jogo e não passamos de peças numa peça cujo enredo é sabido e leva sempre ao mesmo desfecho". ${ }^{5}$ Três metáforas aí se superpõem, formando um único quadro que pinta, como diria Camus, a absurdidade 
da condição humana: 1) a efemeridade e insignificância da espécie humana, micróbio da mosca; 2) o homem como peça de um jogo, ou seja, joguete impotente diante da vida que o domina e ultrapassa; e 3) o próprio enredo da vida humana como um drama cujo desfecho é sempre o mesmo: a morte. A loucura é, portanto, a sabedoria do absurdo da existência humana, consciência da dor, do sofrimento, da arbitrariedade e da morte, por contraposição à burocrática realidade de todos os dias que insiste em esquecer-se, que escolhe deliberadamente a inconsciência e as ilusões várias, os mais diversos anestésicos e as mais burlescas formas de encobrir essa verdade eloquente e gritante da inutilidade de todo esforço humano diante da certeza da morte.

Para o leitor do Camus de O mito de Sísifo, evidentemente, há muitos paralelos a serem traçados. Mas há também, a meu ver, um ponto de encontro entre esse elogio da loucura - e do claune - feito por Campos de Carvalho e alguns temas de $\mathrm{O}$ nascimento da tragédia, talvez precisamente no tocante ao ponto em que o pensamento de Camus remete ao pensamento nietzscheano. É impossível, por exemplo, para o leitor do jovem Nietzsche, ler a passagem da nossa crônica que diz que "só ela [a loucura] nos dá o poder de levitação e voo que teimam, os sujeitos à lei da gravidade, em nos roubar roubando-se a si mesmos" , e não se lembrar da descrição nietzscheana do fenômeno do êxtase dionisíaco que afirma: "ele desaprendeu a dançar e a falar e está a ponto de, dançando, sair voando pelos ares. De seus gestos fala o encantamento". ${ }^{7}$ Para o escritor mineiro, o louco trava uma guerra "antibélica, desnorteando o norte e o sul, o leste e o oeste, um exército de fantasmas e por isso mesmo invencível: meu nome é legião, sou mil em um, e a mim mesmo me estarreço". ${ }^{8}$ Ou seja: assim como o homem grego dionisiacamente excitado, o louco rompe todas as fronteiras impostas pelas convenções da civilização - nomes, sobrenomes e posições sociais estabelecidas - e, unindo-se a tudo o que não é ele mesmo, torna-se muitos, torna-se mil.

Esse paralelo entre a descrição nietzscheana do êxtase dionisíaco e a descrição de Campos de Carvalho da loucura não é de surpreender, evidentemente, quando nos lembramos que o âmbito do dionisíaco é precisamente o da embriaguez: loucura temporária, por assim dizer, que rompe fronteiras e pressupõe o alheamento e a alienação. A visão dionisíaca é precisamente aquela que se aliena da realidade comum para enxergar, lúcida e conscientemente como o louco do literato, a realidade que está em jogo, mas encoberta, por sob o nosso conjunto de verdades mais superficiais. E que mostra, afinal, "derrubando muros e miragens" não é o claune, não é o louco nem tampouco o embriagado, mas sim o mundo comum e insignificante dos objetivos e das metas, dos rumos traçados, pré-determinados e inquestionados ("ele e seus cânones, ele e seus cânceres"10).

Porém - acrescenta ainda o autor ao surpreendente final de sua crônica - "quando morre, o louco procede exatamente como um morto". ${ }^{11}$. Seu semblante revela nada mais que seu sobrenome, embora a família custe a acreditar e cubra-o de flores como que para encobrir o que ainda possa fazer lembrar a loucura do morto. Apenas talvez as 
mãos "crispadas na sua imobilidade"12 possam ser consideradas os vestígios daquele ser, antes sempre à espreita. Ou talvez, como enxergou o narrador no corpo morto do filho louco do Coletor, apenas uns pés e uns dedos emergindo dentre as rosas, "perplexos e perdidos no ar, sem se darem conta ainda da extrema gravidade daquele instante eterno". ${ }^{13}$. O texto termina com essas palavras - e após ter apresentado uma série de contundentes observações necrológicas - sugerindo, todavia, que, ainda que tarde demais, tanto mãos quanto pés dar-se-ão conta; acostumar-se-ão, afinal, à sua medíocre e eterna imobilidade. Terão de habituar-se, forçosamente. Como quem sugere, enfim, que até mesmo a loucura é insuficiente e inútil diante da inexorável verdade do louco, e que a morte a todos engole da mesma forma.

É nesse ponto, então, que mais uma vez o leitor de $O$ nascimento da tragédia há de lembrar-se de alguns comentários do filósofo alemão a respeito do extremo risco inerente à visão dionisíaca da realidade. Esse risco é descrito, no sétimo capítulo, como o perigo da inação e da negação da vida. Poder-se-ia, talvez, complementar: o risco do disforme, do aniquilador. Ao retornar de uma experiência dionisíaca, por assim dizer, o homem sente ainda o travo deixado em sua boca pela consciência do absurdo e, portanto, sente também uma náusea da atuação, um nojo pela necessidade da ação. $\mathrm{O}$ exemplo dado pelo filósofo é Hamlet, aquele que não atua, não pela quantidade de alternativas de que dispõe, mas pela clara noção de que todas as alternativas levam ao mesmo desfecho. Ou seja: que sabe que de nada the adianta agir (e que, poderíamos acrescentar, finge-se de louco para, paradoxalmente, finalmente agir), pois o homem é o micróbio da mosca e a realidade o levará em todo caso à morte, diante da qual todas as ações são destituídas de significado. ${ }^{14}$.

É aí que a teoria da tragédia construída pelo jovem Nietzsche nos acena com uma terceira opção que supera, digamos assim, a dialética entre a lucidez da loucura e as trevas da normalidade tecida por Campos de Carvalho em sua curta crônica. Como se sabe, essa superação, para o autor alemão, vem da aliança entre o apolíneo e o dionisíaco, que é capaz de fazer a tragédia falar das maiores dores da humanidade e mostrar as mortes mais cruéis, sem que com isso aniquile o anelo pela existência. A própria arte unicamente apolínea (como a epopéia, por exemplo), em seus aspectos mais saudáveis e fortes é, segundo Nietzsche, não uma mera inconsciência e encobrimento da experiência dionisíaca (ou seja, não se identifica de modo algum com as "trevas da normalidade"), mas uma proteção de quem se sentiu ameaçado pelo perigo inerente à sabedoria dionisíaca. Proteção que, ainda que se saiba um sonho e uma ilusão, quer continuar se iludindo, quando essa ilusão torna a vida mais desejável porque a celebra e exalta integralmente por meio da criação de belas aparências. ${ }^{15}$. No caso da tragédia, união inédita, segundo Nietzsche, entre os dois impulsos artísticos, a forma apolínea vem fornecer beleza à sabedoria dionisíaca da dor, do sofrimento e da morte, fazendo com que se deseje criar, construir, prosseguir. Prosseguir morrendo e lembrando da morte, não mais como um louco, mas como quem simula a loucura, ou seja, como Hamlet quando age: artisticamente. 
Essa terceira via proposta pela interpretação nietzscheana da tragédia lembra, como não poderia deixar de ser, a terceira via proposta por Camus em O Mito de Sísifo: nem um Sísifo que acalenta a nostalgia da inconsciência - construindo paraísos perdidos e transcendências salvadoras - nem um Sísifo que nada mais faz além de alegar a inutilidade do sofrimento de quem rola sua pedra conscientemente, mas um Sísifo feliz. Um Sísifo a quem o alheamento da realidade mecânica e estéril não implica alienação de todos os seus aspectos, ou inação. Um Sísifo que, nietzscheanamente, constrói montinhos de areia à beira da praia para serem destruídos, em nome da alegria e da beleza de construí-los.

Porém, aqui me dou conta de que talvez esse seja, afinal, o louco de Campos de Carvalho, a construir incessantemente castelos inúteis diante das ondas destruidoras, "locomotiva sem trilhos"16 a errar sem rumo, mas sempre adiante, transbordando sua abundância criativa, gritando "eu, eu, eu, eu,eu"17... Quando morremos, é verdade, somos todos iguais: morto o louco, resta apenas "um rosto e um par de mãos como os de qualquer morto sem maior importância, ali jogados sem o seu misterioso jogo de molas e cordas, em tudo semelhantes ao sono de um burocrata em paz com a sua burocracia". ${ }^{18}$. Não obstante, e ainda assim, pés e dedos a emergirem por entre as rosas, perplexos, estão ali para dar testemunho de que o ponto de vista da morte é nada, se comparado ao ponto de vista da vida. E, ainda que o nada engolfe o tudo, nunca será maior do que ele.

\footnotetext{
* Luisa Buarque é doutora em filosofia pela UFRJ/PPGF.

${ }^{1}$ CAMPOS DE CARVALHO, W. Cartas de viagem e outras crônicas. Rio de Janeiro: José Olympio, 2006, p. 67.

${ }^{2}$ Ibidem, p. 68.

${ }^{3}$ Ibidem, p. 69.

${ }^{4}$ Ibidem, p. 68.

${ }^{5}$ Ibidem, p. 69.

${ }^{6}$ Idem, p. 68.

${ }^{7}$ NIETZSCHE, F. O nascimento da tragédia. São Paulo: Companhia das Letras, 1992, p. 31.

${ }^{8}$ CAMPOS DE CARVALHO, W. Op. cit., p. 68.

${ }^{9}$ Ibidem, p. 68.

${ }^{10} \mathrm{Ibidem}, \mathrm{p} .68$.

${ }^{11}$ Ibidem, p. 70.

${ }^{12}$ Ibidem, p. 70.

${ }^{13}$ Ibidem, p. 71.

${ }^{14}$ A passagem de Nietzsche sobre Hamlet, em $\mathrm{O}$ nascimento da tragédia, é a seguinte: "Nesse sentido, o homem dionisíaco se assemelha a Hamlet: ambos lançaram alguma vez um olhar
} 
verdadeiro à essência das coisas, ambos passaram a conhecer e a ambos enoja atuar; pois sua atuação não pode modificar em nada a eterna essência das coisas, e eles sentem como algo humilhante e ridículo que se lhes exija endireitar de novo o mundo que está desconjuntado. $\mathrm{O}$ conhecimento mata a atuação, para atuar é preciso estar velado pela ilusão - tal é o ensinamento de Hamlet e não aquela sabedoria barata de João, o Sonhador, que devido ao excesso de reflexão, como se fosse por causa de uma demasia de possibilidades, nunca chega à ação; não é o refletir, não, mas é o verdadeiro conhecimento, o relance interior na horrenda verdade, que sobrepesa todo e qualquer motivo que possa impelir à atuação, quer em Hamlet quer no homem dionisíaco". NIETZSCHE, F. Op. cit., N. da T. p. 56.

${ }^{15}$ Aqui é preciso reiterar a impossibilidade de identificar o apolíneo nietzscheano com o âmbito da normalidade medíocre de Campos de Carvalho. A normalidade cotidiana, digamos assim, é certamente apolínea muito mais do que dionisíaca, mas nem toda manifestação apolínea é necessariamente marcada pela inconsciência zumbi e burocrática que Campos de Carvalho atribui à normalidade, por contraposição à loucura. Nietzsche, além disso, ressalta que, na civilização grega, o apolíneo nasceu após o risco da experiência dionisíaca, ou seja, como estratégia de defesa, e não como um estado natural e ingênuo.

${ }^{16}$ CAMPOS DE CARVALHO, W. Op. cit., p. 68.

17 Ibidem, p. 68.

${ }^{18}$ Ibidem, p. 71. 